\title{
Reverse lateral supramalleolar adipofascial flap: A Case Report
}

\author{
Mahdi Ghoncheh $^{1 *(\mathbb{D})}$, Saeid Asghari2 ${ }^{\text {(i) }}$
}

1. Dept. of Plastic and Reconstructive Surgery, Faculty of Medicine, Birjand University of Medical Sciences, Birjand, Iran

2. Dept. of Orthopedic Surgery, Birjand University of Medical Sciences, Birjand, Iran

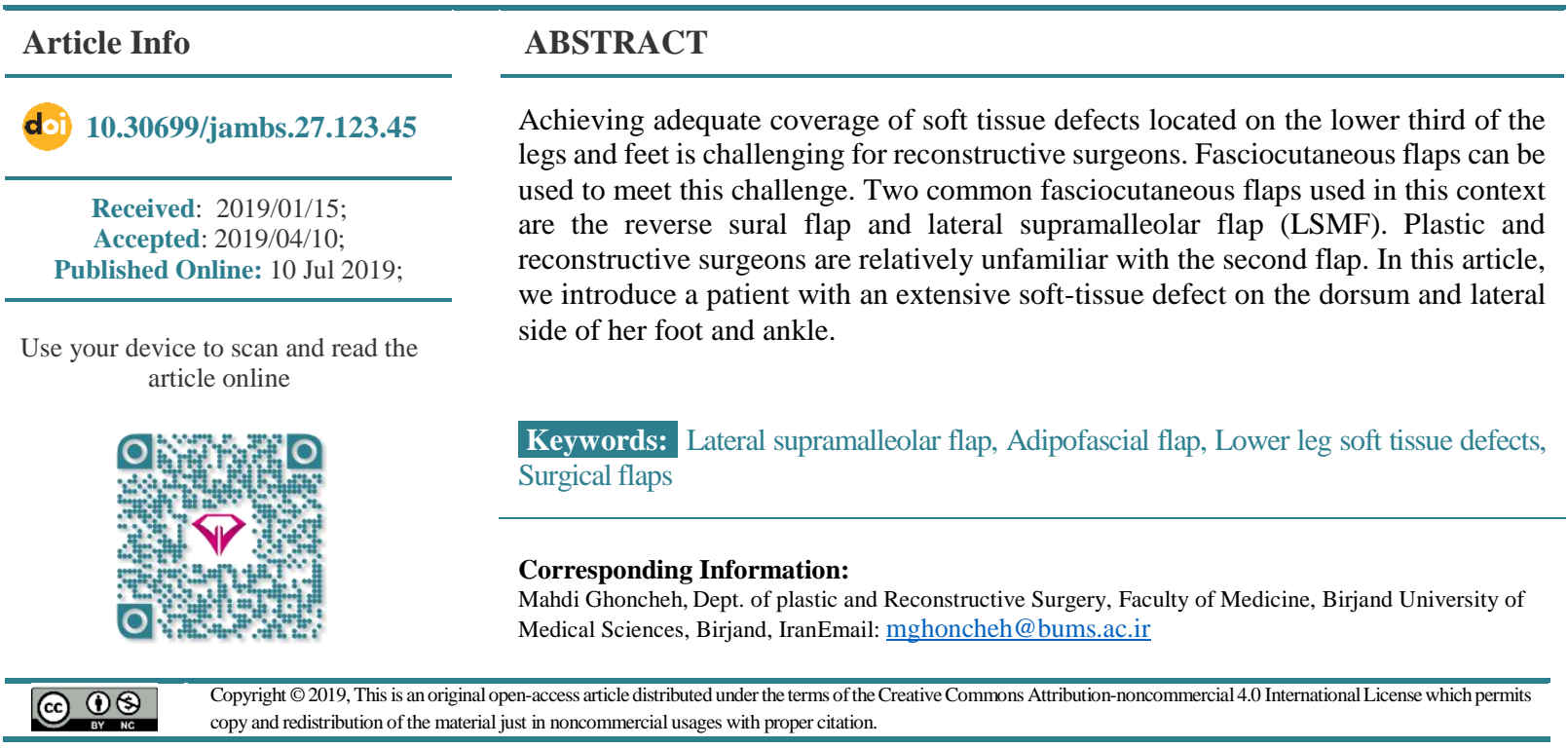

\section{Introduction}

One of challenging for reconstructive surgeons is achieving adequate coverage of soft tissue defects located on the lower third of the legs and feet. In this paper we described a rare method with appropriate outcome.

\section{Case Report}

A 27-year-old woman suffered a large soft-tissue defect of the dorsolateral aspect of the right foot and ankle due to a car accident (Fig. 1).

The anterior and lateral aspects of the ankle joint and calcaneus and talus, along with other bones of the ankle joint, were exposed. The size of the soft-tissue defect was $10 * 6$ centimeters. Since all the lateral ligaments of the ankle were destroyed and because the ankle was unstable, we fixed the ankle using an external fixator. The wound was debrided, and the reconstruction of the defect by means of a lateral supramalleolar flap (LSMF) was performed (Fig. 2).

\section{Operation technique}

The patient was placed in the supine position. The surgical operation was performed with the patient under general anesthesia. A pillow was inserted beneath the right gluteal region of the patient so that the lower limb could be rotated medially. The flap was placed between the anterior border of the fibula and the lateral border of the tibia. The pivotal point of this flap is $5 \mathrm{~cm}$ above the tip of the lateral malleolus on the groove between the tibia and the fibula.

For this reason, the length of the flap was considered to be equal to the length of the defect plus another 5 $\mathrm{cm}$.

A rectangular flap was designed. A curvilinear incision was made in the central axis of the flap so that only the skin was incised. The skin was dissected from the underlying adipofascial layer on both sides of the incision. After that, the adipofascial layer, along with the superficial peroneal nerve, was elevated from proximal to distal. The flap between the anterior tibialis and the extensor digitorum longus muscles continued to be dissected. The flap with a distal pedicle was rotated, and the soft tissue defect was covered by the flap. After some days (Fig. 3) and the formation of granulation tissue, the flap was covered with a skin graft. 


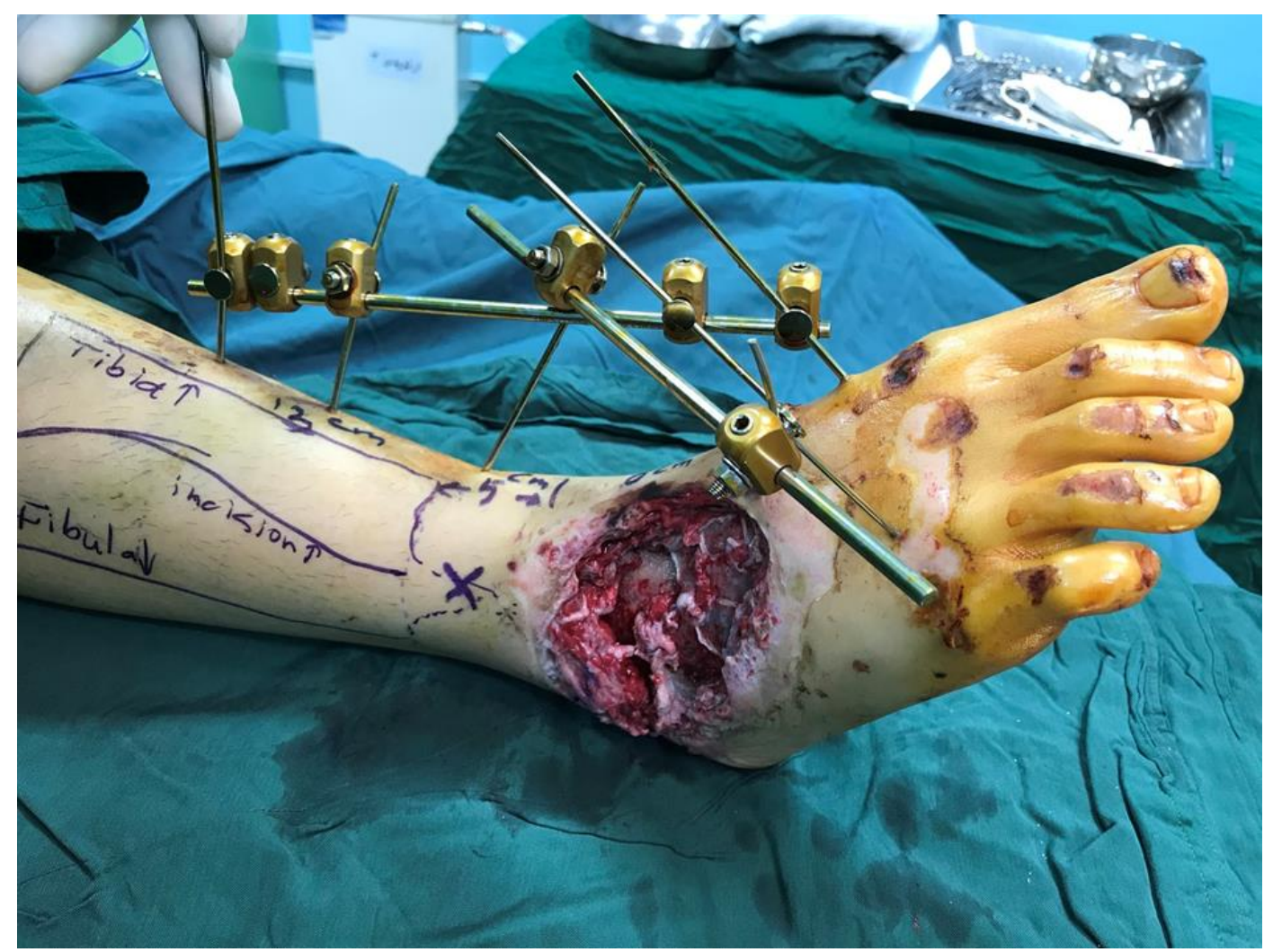

Figure 1. The soft tissue defect

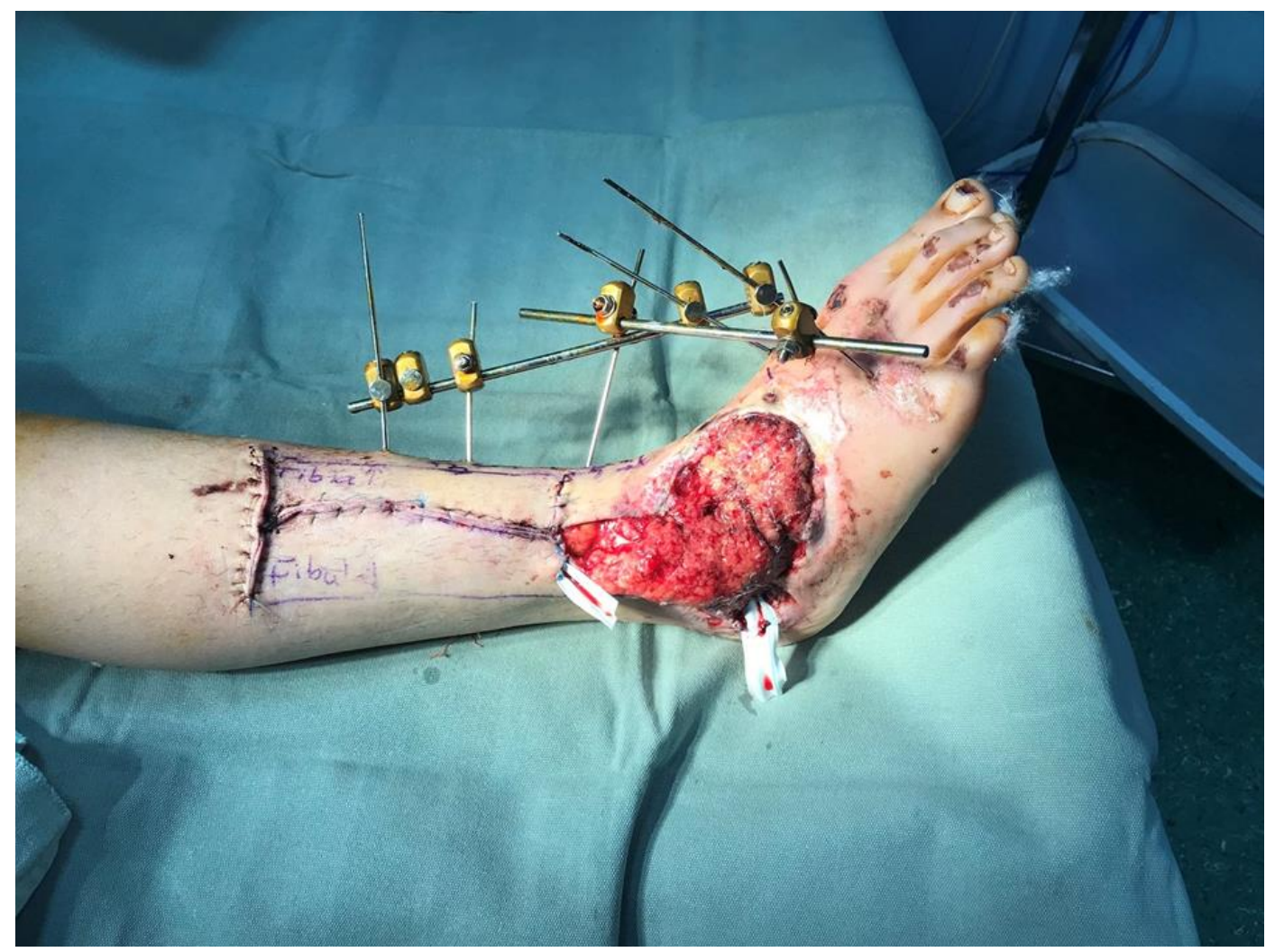

Figure 2. Flap design 


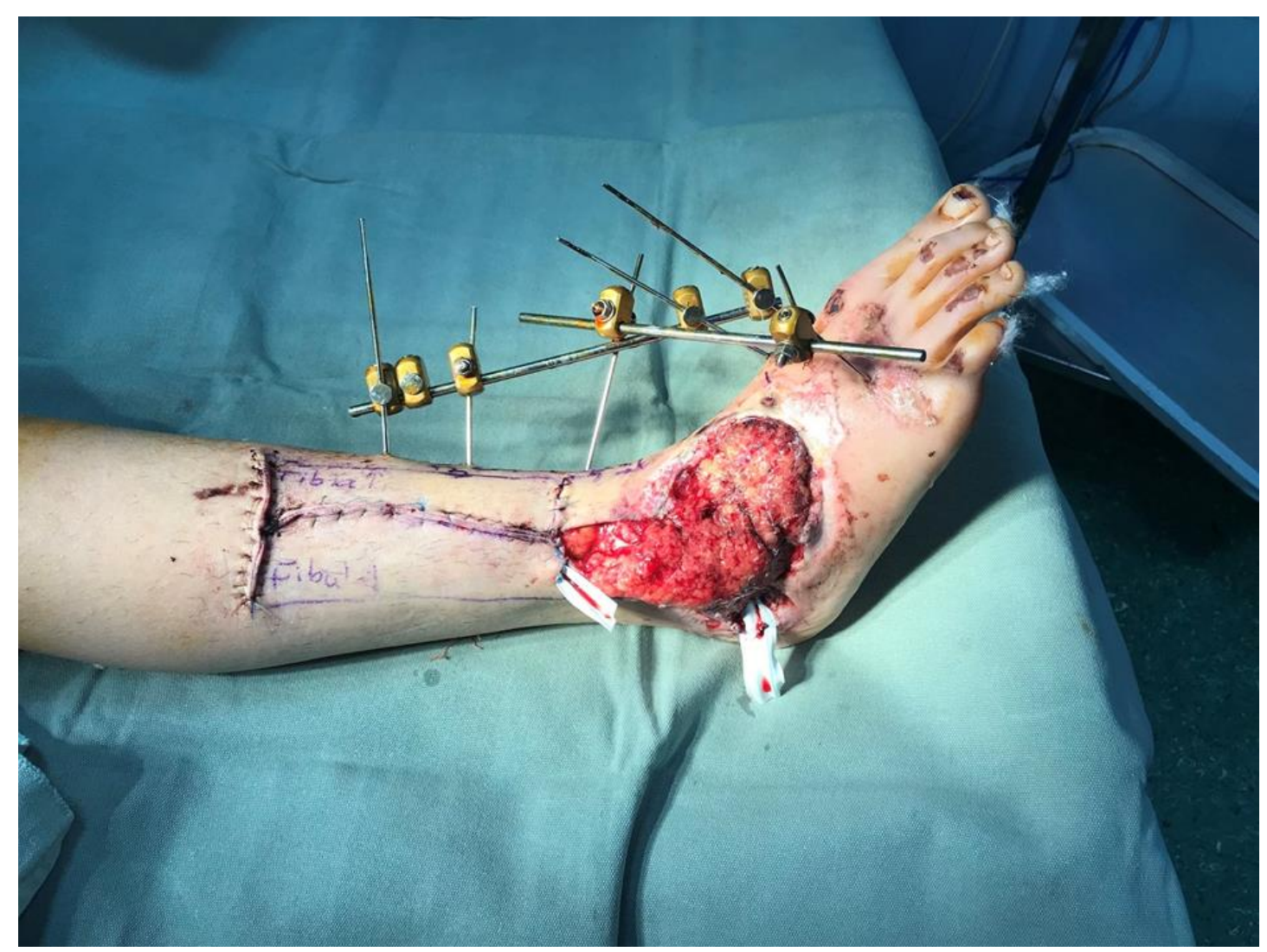

Figure 3. Formation of granulation tissue

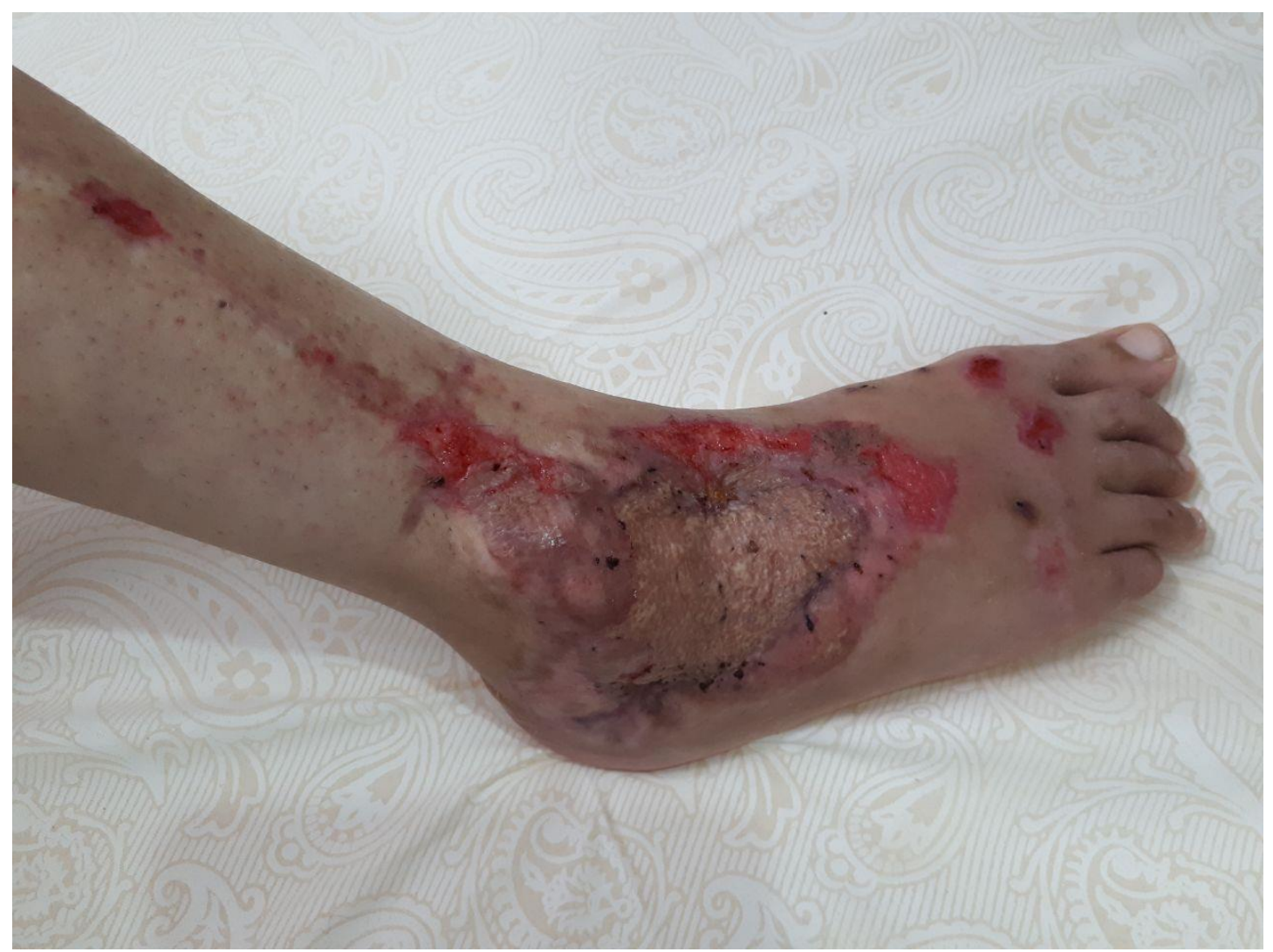

Figure 4. Final result 


\section{Discussion}

Reconstructing the soft tissue of the lower leg, ankle, and foot, especially when bones and joints are exposed, is always a challenge for reconstructive surgeons. The reverse sural flap and LSMF are two options for reconstructing these defects. The LSMF was introduced by Masquelet Aet al. in 1988. The soft tissue defects of the heel, medial of the leg, and ankle, as well as the dorsal, lateral, and plantar aspects of the foot, can be reconstructed by this flap (1). The flap can be designed with a proximal or distal pedicle in the form of a fasciocutaneous or adipofascial and as an island, chimeric, or free flap (2-4).

In many articles, including the early article published by Masquelet et al., the perfusion of this flap is attributed to the perforating branch of the peroneal artery. This branch pierces through the interosseous membrane and is divided into two ascending and descending branches. The ascending branch contributes to the perfusion of the flap. ${ }^{1}$ Rong et al. examined 28 fresh cadaver dissections and showed that, in addition to the perforating branch of the peroneal artery, an anterior branch of the tibial artery, called the "collateral inferolateral branch," also plays a role in perfusion of this flap (5).

According to this study, the perforating branch of the peroneal artery and the inferolateral branch of the anterior tibial artery are anastomoses with each other. In $71.4 \%$ of the cases, the main branches of the flap that perfuse the skin of this region originate from the arterial arch resulting from this anastomosis (5). This flap can be used for reconstruction of the lower leg, ankle, heel, and dorsolateral side of the foot (6). A noteworthy advantage of this flap is that it is thin. Also, during the dissection of the flap, the main arteries of the limb are preserved $(3,4,6)$. In comparison with the reverse sural flap, more distal defects can be reconstructed when using an LSMF (7).

Venous congestion is a common complication associated with this flap (6-8) that occurred in our patient but resolved gradually. It seems that the cause of venous congestion is the compression of the flap pedicle by means of a hematoma or an inelastic skin tunnel (8). This condition could also be caused by the presence of venous valves in lower limb circulation (7). However, the likelihood of this complication occurring can be reduced by ensuring accurate homeostasis and providing a wide subcutaneous tunnel for the passage of the flap (7).

Adipofascial LSMF can be covered either initially (2) or at a later time after the granulation tissue has formed
(6) by means of skin grafts. We covered the flap with a skin graft initially. However, due to necrosis of the tip of the flap, a small portion of the distal flap also required debridement and regrafting. Finally, the wound was healed completely. We think that this flap was cosmetically better than the reverse sural flap (Fig. 4).

\section{Acknowledgements}

The authors thank all those who helped them writing this paper.

\section{Conflict of Interest}

Authors declared no conflict of interests.

\section{References}

1. Goil P, Sharma P, Midya M, et al. The lateral supramalleolar flap: a reliable option for lower leg and foot reconstruction. Int J Res Orthop. 2018;4(5):715-19 [DOI:10.18203/issn.24554510.IntJResOrthop20183222]

2. Lee JH, Chung DW. Reverse lateral supramalleolar adipofascial flap and skin grafting for one-stage soft tissue reconstruction of foot and ankle joint. Microsurgery.2010; 30(6):423-29. [DOI:10.1002/micr.20762]

3. Okazaki M, Ueda K, Niu A, et al. Free lateral supramalleolar flap transfer as a small, thin flap. Ann Plast Surg. 2002; 49(2):133-37.

4. Massarelli O1, Gobbi R, Biglio A, Soma D, Tullio A. Chimeric lateral supramalleolar artery perforator fibula free flap in the reconstruction of composite head and neck defects. Plast Reconstr Surg. 2014; 133(1):130-6 [DOI:10.1097/01.prs.0000435845.33670.64]

5. Rong K1, Chen C, Hao LW, Xu XY, Wang ZT. Redefining the vascular classifications of the lateral supramalleolar flap. Ann Plast Surg. 2016; 77(3):341-4 [DOI:10.1097/SAP.0000000000000576]

6. Demiri E1, Foroglou P, Dionyssiou D, et al.Our experience with the lateral supramalleolar island flap for reconstruction of the distal leg and foot: a review of 20 cases. Scand J Plast Reconstr Surg Hand Surg. 2006; 40(2):106-10 [DOI:10.1080/02844310500523740]

7. Voche P1, Merle M, Stussi JD.The lateral supramalleolar flap: experience with 41 flaps. Ann Plast Surg. 2005; 54(1):49-54 [DOI:10.1097/01.sap.0000139565.36738.b3]

8. Hamdi MF1, Khlifi A. Lateral supramalleolar flap for coverage of ankle and foot defects in children.J Foot Ankle Surg. 2012;51(1):106-9 [DOI:10.1053/i.jfas.2011.10.014]

\section{How to Cite This Article:}

Ghoncheh M, Asghari S. Reverse Lateral Supramalleolar Adipofascial Flap: A Case Report. J Adv Med Biomed Res. 2019; 27 (123):45-48

Download citation:

$\underline{\text { BibTeX }}|\underline{\text { RIS }}| \underline{\text { EndNote }}|\underline{\text { Medlars }}| \underline{\text { ProCite }}|\underline{\text { Reference Manager }}| \underline{\text { RefWorks }}$

\section{Send citation to:}

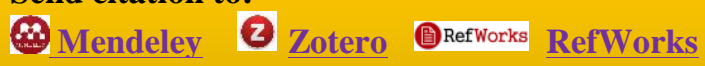

